\title{
TENSÕES E CONFLITOS NA GOVERNANÇA DOS RECURSOS HÍDRICOS AMAZÔNICOS TRANSFRONTEIRI ÇOS
}

Fernanda Mello Sant'Anna

Resumo: Este trabalho analisa as tensões e conflitos sociais existentes na governança dos recursos hídricos transfronteiriços amazônicos, e faz um estudo de duas regiões amazônicas, a região MAP (na fronteira entre Peru, Brasil e Bolívia) e a bacia do rio Napo (na fronteira entre Equador e Peru). Nestas regiões estão sendo implementados projetos pilotos de gerenciamento integrado dos recursos hídricos transfronteiriços, que fazem parte de um projeto maior de gestão dos recursos hídricos da bacia amazônica como um todo. Desta forma, busca-se analisar por meio de pesquisa bibliográfica, documental e por dados gerados em campo, estas duas iniciativas de projetos pilotos de gerenciamento integrado dos recursos hídricos transfronteiriços da bacia amazônica.

Palavras-chave: Recursos hídricos, transfronteiriço, Amazônia, conflitos, cooperação.

\section{TENSIONS AND CONFLICTS IN THE GOVERNANCE OF TRANSBOUNDARY WATER RESOURCES IN THE AMAZON}

\section{Abstract}

This work aims to analyze the social conflicts and tensions involved in the governance of Amazon transboundary water resources, and studies two Amazon regions, the MAP region (in the border of Peru, Brazil and Bolivia) and the Napo river basin (in the border of Ecuador and Peru). In this regions are been implemented pilot projects of integrated management of transboundary water resources, that are part of a wider project to manage transboundary water resources in the Amazon basin as a whole. Therefore, the analysis of this two pilot projects initiatives to manage the transboundary water resources in the Amazon basin is based on bibliographical and documental research, and in data collected from the field.

Key words: Water resources, transboundary, Amazon, conflicts, cooperation.

\section{I ntrodução}

A governança dos recursos hídricos transfronteiriços é marcada por tensões e conflitos, visto que grande parte das bacias compartilhadas não possuem mecanismos eficientes de cooperação e gestão dos seus recursos hídricos.

Neste trabalho, o objetivo é analisar a governança dos recursos hídricos transfronteiriços da bacia amazônica, em especial, a região MAP e a bacia do rio Napo que são regiões onde estão sendo implementados iniciativas de projetos pilotos de gerenciamento integrado dos recursos hídricos transfronteiriços. Estes projetos piloto fazem parte de um projeto maior de gestão dos recursos hídricos da bacia amazônica como um todo, realizado pela parceria entre a Organização do Tratado de Cooperação Amazônica (OTCA), o Fundo Mundial para o Meio Ambiente (Global 
Tensão e conflitos na governança dos recursos hídricos amazônicos transfronteiriços. SANT'ANNA.

Environment Facility - GEF - sigla em inglês) e o Programa das Nações Unidas para o Meio Ambiente (PNUMA). Nas regiões dos projetos pilotos há também projetos e propostas de projetos da Iniciativa para a Integração da Infraestrutura Regional Sul-Americana (IIRSA) que apresentam impactos sociais e ambientais e tem gerado tensões e conflitos entre diferentes atores.

A análise está baseada em pesquisa bibliográfica, documental e por dados gerados em campo, utilizando-se, para tanto, fontes secundárias e primárias. O trabalho começa como uma revisão das teorias sobre governança e gestão de recursos hídricos transfronteiriços. Em seguida, é apresentada a bacia amazônica e o projeto de gestão da bacia, para então analisar o caso da bacia do rio Acre na região MAP e a bacia do rio Napo.

\section{A governança dos recursos hídricos transfronteiriços}

O uso do termo governança por muitas instituições e em seus documentos oficiais tem demonstrado que existem diferentes definições e sentidos para o termo, que depende das visões e valores dos atores que o utilizam. Por isso, existe um embate político sobre o conteúdo da governança da água, visto que reflete políticas diferentes e até opostas (CASTRO, 2007).

Apesar do uso do termo governança de forma instrumental, a governança não é apenas um instrumento de políticas, e sim o processo de tomada de decisão relacionado à formulação de políticas de como gerir os recursos hídricos. Este é um processo político em que diversos atores debatem e tentam acordar os objetivos a serem perseguidos, os valores e princípios, e os instrumentos utilizados para a gestão dos recursos hídricos. O modo como estas questões são tratadas e discutidas, e a forma de tomada de decisões, é que configuram o processo de governança da água. Assim, quem participa, como participa e como são tomadas as decisões é o que realmente configura a governança (CASTRO, 2007; LAUTZE, 2011).

A diferença entre governança da água e gestão da água é que a governança é o conjunto de processos e instituições que definem e identificam quais são as metas de gestão a serem perseguidas. A gestão trata dos mecanismos e medidas práticas utilizadas para atingirem as metas traçadas e, portanto, atingir melhores resultados (LAUTZE, 2011). Dito de outra forma, a governança da água fornece a estrutura para decidir quais serão as atividades de gestão dos recursos hídricos que serão implementadas (LAUTZE, 2011). Deste modo, pode-se inferir que uma crise da governança da água é uma crise nos processos de tomada de decisão e das instituições, ou seja, os princípios da boa governança não estão sendo implementados.

Tomando a escala da bacia hidrográfica, o compartilhamento dos recursos hídricos transfronteiriços pode resultar em conflitos e/ou cooperação. A abordagem da gestão por bacias tem implicações para a organização institucional, pois se realiza segundo os limites naturais da bacia e não segundo as fronteiras políticoadministrativas dos municípios, estados e países.

De acordo com Postel e Wolf (2001 apud Gerlak, 2007), 263 rios do mundo são compartilhados entre dois ou mais países. E, desta forma, a água possui uma natureza política, pois a sua apropriação e controle interessa a todas as coletividades humanas (RAFFESTIN, 1990). Sua apropriação depende do acesso a este recurso que se tem no território. No entanto, "a distribuição 
Tensão e conflitos na governança dos recursos hídricos amazônicos transfronteiriços. SANT'ANNA.

natural da água pelo mundo não coincide com a ocupação humana, gerando pontos de tensão e luta por água doce" (RIBEIRO, 2008, 131).

O conflito e a cooperação, em geral, coexistem em uma bacia hidrográfica compartilhada, por isso, é preciso levar em conta o contexto político em que se dão as relações entre os Estados que compartilham a bacia (MIRUMACHI e ALLAN, 2007).

Como um processo político, as interações entre os países em relação às águas transfronteiriças podem servir a diversos objetivos estratégicos, tais como, para atrair financiamento externo, ou dividir o peso dos custos de descontaminação. Estas estratégias podem estar baseadas nas assimetrias de poder entre os países (ZEITOUN e MIRUMACHI, 2010). Desta forma, não se pode analisar a cooperação apenas a partir de indicativos como a assinatura de tratados ou o estabelecimento de organizações de bacias. Para se considerar uma cooperação como efetiva é preciso que seja feita uma análise a partir de suas múltiplas faces, como a complacência, interesses, objetivos e mecanismos para a resolução dos conflitos entre os países (ZEITOUN e MIRUMACHI, 2010, p. 113). Além disso, é preciso levar em conta que tipo de cooperação se trata, pois nem sempre a cooperação para o aproveitamento dos recursos hídricos transfronteiriços resulta em melhorias ambientais. Como demonstra Sneddon e Fox (2006), muitos países em desenvolvimento possuem acordos de cooperação, mas que, em geral, são para o aproveitamento hidrelétrico de bacias transfronteiriças. Deste modo, com base nas teorias apresentadas, busca-se analisar dois estudos de caso na bacia amazônica.

\section{A governança e gestão da Bacia Amazônica}

A Bacia Amazônica é compartilhada por sete países (Bolívia, Brasil, Colômbia, Equador, Guiana, Peru, e Venezuela), que fazem parte da OTCA (o Suriname faz parte da organização, mas não compartilha a bacia).

A superfície da bacia amazônica, de acordo com os dados do estudo GEOAMAZÔNIA realizado pelo Programa das Nações Unidas para o Meio Ambiente (PNUMA), pela OTCA e pelo Centro de Investigações da Universidade do Pacífico (CIUP) (PNUMA, OTCA e CIUP, 2009), varia nos estudos sobre a região, de acordo com o critério utilizado, de $6.100 .000 \mathrm{~km}^{2}$ até mais de 7 milhões $\mathrm{km}^{2}$.

Pelo critério hidrográfico, a diferença dos dados se deve pela exclusão dos rios Tocantins e Araguaia, bem como de seus afluentes, da bacia do Amazonas. Se a bacia do Tocantins, que tem uma superfície aproximada de $900.000 \mathrm{~km}^{2}$, for incluída nesse quesito a área da bacia passa de $6.118 .334 \mathrm{~km}^{2}$ para $7.018 .334 \mathrm{~km}^{2}$. Alguns países como a Venezuela e a Bolívia utilizam o critério hidrográfico na definição políticaadministrativa da Amazônia. Já pelo critério ecológico (domínio amazônico) a área total da Amazônia é maior que a área da bacia hidrográfica do rio Amazonas, com uma diferença de $707.087 \mathrm{~km}^{2}$.

O gerenciamento dos recursos hídricos transfronteiriços amazônicos

Devido a sua condição de bacia transfronteiriça, em 2002, na 11a Reunião do Conselho de Cooperação Amazônica da OTCA, os países decidiram pela realização de 
Tensão e conflitos na governança dos recursos hídricos amazônicos transfronteiriços. SANT'ANNA.

um projeto de gerenciamento conjunto dos recursos hídricos amazônicos. No ano seguinte, foi apresentado ao GEF o Projeto "Gerenciamento Integrado e Sustentável dos Recursos Hídricos Transfronteiriços na Bacia do Rio Amazonas Considerando a Variabilidade e as Mudanças Climáticas", que foi aprovado com um fundo de setecentos mil dólares (U\$ 700.000,00). Desta forma, a OTCA juntamente com a OEA e o PNUMA assinaram em 2005 um acordo para a execução da fase preparatória do Projeto, chamada PDF bloco B, que teve duração de vinte três meses, de 21 e outubro de 2005 a 21 de setembro de 2007.

A fase preparatória do Projeto teve como meta a elaboração de um documento de Projeto na sua versão completa, o detalhamento dos componentes do Projeto e a definição de uma visão consensual de desenvolvimento sustentável para a bacia do rio Amazonas. Esta fase apresentou cinco componentes: a visão da Bacia, o fortalecimento institucional, o prognóstico dos impactos hidrológicos decorrentes das mudanças climáticas, o gerenciamento integrado dos recursos hídricos, e a participação pública neste gerenciamento.

O objetivo geral do projeto é:

fortalecer o marco institucional para planejar e executar, de maneira coordenada, as atividades de proteção e gerenciamento sustentável dos recursos hídricos em face dos impactos decorrentes das ações antrópicas e mudanças climáticas na Bacia Amazônica (OTCA, 2007a).

A segunda fase do Projeto conta também com o financiamento do GEF, e o PNUMA como instituição executora do financiamento. O projeto contém quatro componentes: 1) Compreendendo a Sociedade Amazônica ${ }^{1}$; 2) Entendendo a

$1 \quad$ Tradução livre da autora. base natural da bacia do rio Amazonas; 3) Estratégias de Resposta; 4) Administração do Projeto. Cada componente está dividido em subprojetos que, por sua vez, se subdividem em atividades.

O terceiro componente "Estratégias de Resposta" apresenta 5 subprojetos: 1) Projetos Pilotos de Gerenciamento Integrado dos Recursos Hídricos (GIRH) na Bacia do rio Amazonas; 2) Prioridades especiais em adaptação na Bacia do rio Amazonas; 3) Sistema de Informação Integrada; 4) Comunicação, Alcance e Finança; 5) Programa de Ação Estratégica.

O primeiro subprojeto "Projetos Pilotos de GIRH na Bacia do rio Amazonas" contém quatro atividades: 1) Manejo de Ecossistemas Aquáticos Hotspots; 2) Manejo sustentável de Florestas inundadas Transfronteiriças na Bacia do rio Amazonas; 3) Uso sustentável da água subterrânea nos centros urbanos amazônicos: o caso de Manaus (Brasil); 4) Gerenciamento Integrado de Bacia Transfronteiriça nas regiões amazônicas de Napo e MAP.

O foco de análise deste trabalho é a quarta atividade deste subprojeto, que se trata de dois projetos pilotos de gestão transfronteiriça dos recursos hídricos. Um deles se localiza na região da fronteira entre Peru, Brasil e Bolívia, conhecida como MAP (Madre de Dios, Acre e Pando) e o segundo na bacia transfronteiriça no rio Napo, na fronteira entre Equador e Peru.

Os resultados esperados deste subprojeto são o aumento da capacidade das comunidades e stakeholders das microbacias implementarem atividades piloto de gerenciamento integrado dos 
Tensão e conflitos na governança dos recursos hídricos amazônicos transfronteiriços. SANT'ANNA.

recursos hídricos na bacia amazônica que tratem das principais preocupações transfronteiriças compartilhadas pelos países da bacia (OTCA, PNUMA e GEF, 2009). Espera-se que a reprodução dos resultados das atividades em outros locais da bacia melhore a qualidade e sustentabilidade das políticas, planos e programas de gerenciamento integrado dos recursos hídricos, como definido no Programa de Ação Estratégico (PAE).

Esta quarta atividade prevê três elementos principais. O primeiro é a organização de reuniões no âmbito da microbacia para identificar as preocupações da comunidade em relação ao gerenciamento integrado dos recursos hídricos. Este item conta com a realização de workshops com os atores sociais envolvidos.

O segundo elemento se concentra na definição de um conjunto de ações estratégicas como resposta às preocupações identificadas no elemento anterior. Já o terceiro elemento trata de implementar ações estratégicas de demonstração local consistentes com as diretrizes do gerenciamento integrado dos recursos hídricos em áreas piloto selecionadas.

No entanto, a segunda fase está paralisada, conforme foi comprovado por entrevistas realizadas com a equipe da OTCA e diplomatas envolvidos com o projeto, bem como, funcionários da ANA, durante pesquisa de campo realizada em julho de 2010. Esta paralisação se deve a divergências entre alguns países da OTCA sobre a continuidade do projeto. Todavia, a OTCA busca relançar esta segunda fase assim que estes conflitos estiverem solucionados.
Isto demonstra uma grande fragilidade da organização e até mesmo da cooperação em torno dos recursos hídricos transfronteiriços. Diversos autores (COSTA-FILHO, 2003; CAUBET, 2006) tem demonstrado a fragilidade institucional da OTCA para lidar com a gestão dos recursos hídricos transfronteiriços, e com a resolução pacífica de conflitos, além de apontarem algumas divergências de interesses, que em certos momentos atuam como obstáculo à cooperação. No entanto, nos últimos anos se tem notado uma maior cooperação em relação ao aproveitamento hidrelétrico dos recursos hídricos amazônicos, inclusive próximos às fronteiras, o que não causa melhoras ao ambiente e, sim impactos tanto ambientais quanto sociais. Como é o caso do acordo bilateral entre Brasil e Peru para construção de hidrelétricas na Amazônia peruana e exportação dos excedentes de energia ao Brasil (ALVAREZ e FADIGAS, 2010).

\section{Delimitação geográfica das áreas de estudo: a região MAP e a bacia do rio Napo}

As regiões onde estão sendo realizados os dois projetos pilotos de gerenciamento integrado dos recursos hídricos transfronteiriços, a região MAP e a bacia do rio Napo, contam com certa organização de alguns grupos em torno da gestão das bacias transfronteiriças.

Cabe ressaltar que ambas alojam projetos da IIRSA lançada em 2000 pelos governos dos doze países sul-americanos. A IIRSA tem o apoio da CAF, do Banco Interamericano de Desenvolvimento (BID) e 
Tensão e conflitos na governança dos recursos hídricos amazônicos transfronteiriços. SANT'ANNA.

do Fundo Financeiro para o Desenvolvimento da Bacia do Prata (FONPLATA). Na região MAP está presente o projeto da Estrada do Pacífico que faz parte do Eixo Peru-BrasilBolívia. Este é também um eixo transversal, ele abarca os departamentos peruanos de Tacna, Moquegua, Arequipa, Apurimac, Cusco, Puno y Madre de Dios, dois departamentos bolivianos, Pando e Beni, e quatro estados do Brasil : Acre, Rondônia, Amazonas e Mato Grosso. Na bacia do rio Napo está previsto a implantação do projeto da IIRSA de navegabilidade do rio Napo, com a construção de uma hidrovia, e faz parte do eixo do Amazonas binacional Manta-Manaus, que busca ligar o porto de Manta no Pacífico à cidade de Manaus (IIRSA, 2008).

Governança de baixo pra cima na bacia do rio Acre na região MAP

A região de Madre de Dios (Peru), Acre (Brasil) e Pando (Bolívia), denominada MAP, corresponde à tríplice fronteira entre estes três países e está situada na Amazônia Sul Ocidental. Esta região compartilha diversas bacias transfronteiriças, como é o caso da bacia do rio Acre ${ }^{2}$, onde existe uma iniciativa de gestão trinacional.

A proposta do Programa de Gestão Integrada da Bacia Trinacional do Alto Rio Acre surgiu de demandas apresentadas pelas

\footnotetext{
${ }^{2}$ A bacia do rio Acre tem aproximadamente 7.577 $\mathrm{km}^{2}$, com $3.181 \mathrm{~km}^{2}$ no Brasil (41\% da área da bacia), $2.560 \mathrm{~km}^{2}$ no Peru (33\% da área da bacia), e $1.936 \mathrm{~km}^{2}$ na Bolívia ( $26 \%$ da área da bacia). O rio Acre origina-se no Peru, em uma altitude de aproximadamente entre $300 \mathrm{~m}$ e $400 \mathrm{~m}$ próximo à fronteira com o Brasil (DUARTE, 2008; MT; 2008; REIS et al., 2007), sendo um afluente da margem esquerda do rio Purus. Flui no sentido SudoesteNordeste, onde deságua no rio Purus, na cidade Boca do Acre (Brasil).
}

comunidades da Região MAP, em 2002, no III Fórum MAP. Este fórum teve como objetivo principal o fortalecimento das ações colaborativas e de integração regional (MINIMAP BACIA, 2007).

A proposta de um Programa de Gestão Integrada da Bacia Trinacional do Alto Rio Acre teve inicio em 2003, quando foi criado o Consórcio de Desenvolvimento Intermunicipal do Alto Acre e Capixaba (CONDIAC) que foi implementado oficialmente em 2004, juntamente com a estruturação da Comissão de Integração Regional e Internacional. Esta Comissão propôs a criação de um comitê trinacional para que os consórcios municipais firmassem acordos para atividades na região da tríplice fronteira. Assim, nasce o Comitê dos Municípios de Fronteira da Região MAP formado por um grupo de cinco municípios de cada país, no Brasil pelo CONDIAC, na Bolívia pela MANCOMUNIDAD TAHUAMANU e no Peru pelo consórcio AMFROMAD. Este Comitê conta ainda com a participação de representantes dos governos municipais, representantes dos Ministérios das Relações Exteriores dos três países e de representantes da sociedade civil.

Em 2004, durante a realização do quinto Fórum MAP, em Puerto Maldonado, Peru, foi assinado um Convênio Marco entre instituições dos três países para desenvolver e implementar atividades e projetos de pesquisa e de desenvolvimento sustentável, promover a troca de informações sobre a região, entre outros objetivos. As instituições envolvidas no convênio estabeleceram um Plano de Trabalho para a gestão da Bacia Trinacional do Alto Rio Acre. Este Plano envolve diversos subprogramas.

Em 2006 a WWF-Brasil (World Wild Fund) organizou a "Oficina Aspestos Legais e Ações Estratégicas para a Gesão 
Tensão e conflitos na governança dos recursos hídricos amazônicos transfronteiriços. SANT'ANNA.

Compatilhada da Bacia Trinacional do Rio Acre - Brasil, Bolívia e Peru", que contou com a presença de instituições dos três países com o objetivo de discutir os aspectos legais da gestão dos recursos hídricos transfronteiriços. Esta oficina resultou em um primeiro rascunho sobre as linhas gerais a serem seguidas na gestão da bacia do rio Acre.

Após esta reunião o governo brasileiro criou um Grupo de Trabalho sobre a bacia transfronteiriça do rio Acre que conta com a presença de representantes da ANA, do Ministério das Relações Exteriores, do governo estadual e dos governos municipais. O GT tem como objetivo:

\begin{abstract}
a elaboração de um plano de trabalho para apoiar a promoção da gestão articulada da Bacia do rio Acre, mediante a ação coordenada dos organismos responsáveis pela gestão ambiental e dos recursos hídricos no Brasil, na Bolívia e no Peru, contando com a participação ativa dos organismos regionais e locais e da sociedade civil, compreendendo ações de curto, médio e longo prazos (ALMEIDA, REIS, SILVA, 2009).
\end{abstract}

Ele foi criado em 2006 no Brasil, junto a Câmara Técnica de Gestão de Recursos Hídricos Transfronteiriços (CTGRHT) do Conselho Nacional de Recursos Hídricos (CNRH). Este grupo funcionou até 2010, quando foram encerrados os trabalhos e um relatório foi apresentado à CTGRHT para ser analisado, e ele faz as seguintes recomendações:

O Grupo de Trabalho do Rio Acre, em vista do exposto acima, e com o principal objetivo de contribuir para o desenvolvimento da gestão integrada de recursos hídricos compartilhados entre Brasil, Peru e Bolívia na bacia hidrográfica do Rio Acre, propõe à CTGRHT o seguinte curso de ação: a) envio de moção ao CNRH para mobiliar os atores pertinentes a assinarem acordo trilateral para a gestão integrada da bacia hidrográfica do Rio Acre (Anexo I); b) negociação e assinatura de acordo bilateral nos moldes da proposta apresentada no Anexo II; c) após a assinatura do acordo, realização de seminário trinacional para a mobilização dos atores nacionais e locais para a implantação do acordo assinado (SAMPAIO, 2010).

O GT do Rio Acre apontou como principais conflitos na bacia:
a) a dificuldade de abastecimento urbano e de navegação nas épocas de seca; b) enchentes nas épocas de cheia; c) conflitos sobre a pesca na época da defesa, por disparidade na legislação a respeito nos três países; d) deslocamento do leito do Rio Acre nos meandros ocasionando mudança física nas fronteiras, com a possibilidade de transferência de comunidades inteiras para o país vizinho; e) uso irregular da navegação para transporte de produtos ilegais; f) necessidade de manutenção do caudal ecológico nas épocas de seca (SAMPAIO, 2010).

As mudanças sazonais que ocorrem na região geram grande variação do regime dos rios da bacia do rio Acre, ocasionando, alternadamente, enchentes e secas, que tem afetado de forma negativa a população local. $\mathrm{Na}$ época de seca o nível do rio Acre e de seus afluentes pode chegar a ser tão baixo que dificulta o abastecimento de água potável e a pesca. E na época das chuvas podem ocorrer enchentes inundando bairros e casas, deixando famílias desabrigadas.

Além disso, observa-se que a alteração do curso do rio Acre, isto é, o deslocamento do leito nos meandros, tem levado a uma mudança nas fronteiras, pois o rio é utilizado como o demarcador do limite entre os países. De forma que, partes das cidades gêmeas podem acabar sendo transferidas para o país vizinho. Isto está ocorrendo na cidade de Brasiléia, no Brasil, que faz fronteira com Cobija, na Bolívia, onde um bairro está prestes a ser cortado da 
Tensão e conflitos na governança dos recursos hídricos amazônicos transfronteiriços. SANT'ANNA.

cidade e passará para o lado boliviano, o que tem gerado grandes preocupações para os governos municipais.

Brito (2007) aponta como os três principais problemas socioambientais da região MAP: os impactos da Estrada do Pacífico, a gestão dos recursos hídricos e o aumento do desmatamento. A Estrada do Pacífico é aquela que liga o Brasil aos portos peruanos no Pacífico, como parte do projeto da IIRSA. No Brasil a estrada é chamada de BR-317 e já foi asfaltada. No lado peruano as obras já foram iniciadas e contam com o financiamento do Banco Nacional de Desenvolvimento Econômico e Social (BNDES), da Corporação Andina de Fomento (CAF) e do governo peruano (BRITO, 2007).

A preocupação socioambiental em relação a esta estrada se deve aos impactos que pode causar como a intensificação do desmatamento e dos incêndios florestais. Para Dourojeanni (2001) entre os impactos destaca-se: desmatamento, aumento dos riscos de incêndios, caça ilegal, erosão dos solos, invasão de áreas protegidas, perda de biodiversidade, aumento das atividades ilegais como o narcotráfico, formação de favelas, entre outros.

As dificuldades da governança e gestão da bacia do rio Napo

Já a região da bacia do rio $\mathrm{Napo}^{3}$ está localizada na fronteira entre Equador e Peru, faixa que foi palco de conflitos territoriais que duraram quase cem anos. Após o acordo de

\footnotetext{
3 O rio Napo é um afluente da margem esquerda do rio Amazonas, nasce nas montanhas de Cotopaxi, no Equador. Sua bacia se divide em Alto Napo e Baixo Napo. O Alto Napo compreende desde a nascente até a desembocadura do rio Coca (em território equatoriano), quando tem início o Baixo Napo chegando até a sua desembocadura no rio amazonas, próximo à cidade de Iquitos, no Peru.
}

paz de 1998, os dois países assinaram o Acordo Amplo peruano-Equatoriano de Integração Fronteiriça, Desenvolvimento e Vizinhança, no qual está inserido o Plano Binacional de Desenvolvimento da Região Fronteiriça, que conta com um Fundo Binacional Peru-Equador. Neste mesmo ano também foi assinado o Tratado de Comércio e Navegação entre Equador e Peru.

O Tratado de Comércio e Navegação visa assegurar a navegação pacífica e o comércio no rio Amazonas e seus afluentes, permitindo que o Equador utilize os rios que dão acesso ao rio Amazonas em território peruano. Este tratado contempla a igualdade de tratamento e reciprocidade na navegação fluvial, no transito terrestre e no comércio entre os dois países. Ainda prevê um sistema de solução de controvérsias com o estabelecimento de uma comissão PeruanoEquatoriana de Comércio e Navegação que tem competência para resolver os conflitos.

No Plano Binacional estão inseridos inúmeros projetos que visam o desenvolvimento das regiões fronteiriças entre estes países. Encontra-se, aí, o Plano Binacional Peruano-Equatoriano para o Desenvolvimento das Bacias dos rios Napo, Tigre e Pastaza (EQUADOR e PERU, 2010).

O Plano prevê projetos binacionais e programas nacionais para serem executados nas regiões fronteiriças. Um dos objetivos do Programa de Projetos Binacionais é a gestão adequada das bacias hidrográficas comuns a ambos os países. Um dos projetos é o chamado Estudos hidromorfológicos para Navegação, que está sob responsabilidade do Ministério de Transportes, Comunicação, Habitação e construção do Peru, e da Oficina do Plano Binacional de Desenvolvimento da Região Fronteiriça na parte equatoriana. Estes estudos tem como objetivo servir de base para a possibilidade da utilização 
Tensão e conflitos na governança dos recursos hídricos amazônicos transfronteiriços. SANT'ANNA.

comercial do sistema fluvial peruanoequatoriano, que poderia contar com um corredor de transporte fluvial que conecte ambos Estados e destes com outros dentro da bacia amazônica. Serão analisados portanto, os rios Napo, Tigre, Corrientes, Pastaza, Marañón e Santiago. (QUEROL, 2003).

Na bacia do rio Napo está prevista a implantação de um projeto da IIRSA de navegabilidade do rio Napo, que prevê a construção de uma hidrovia. O Eixo do Amazonas contém o Grupo de Projetos $n^{\circ} 6$ "Rede de Hidrovias Amazônicas", cujo objetivo é melhorar a navegabilidade dos rios Amazonas, Solimões, Ica, Putumayo, Huallaga, Marañon, Ucayali, Napo e Morona, em uma extensão estimada de $8.500 \mathrm{~km}$. Dentro deste conjunto de projetos está o “G2 - Acesso à Hidrovia do Napo", cujo projeto âncora é o do Porto de Francisco de Orellana, e que conta com a função estratégica de fortalecer a integração nacional equatoriana em sua porção amazônica, nas províncias de Napo e Orellana com a serra e a costa, e também permite consolidar uma via fluvial equatoriana até Manaus contribuindo para a integração regional amazônica e também conectando até a Costa do Pacífico. Também conta com os seguintes projetos: Centro Binacional de Atenção de Fronteira (CEBAF) Nuevo Roca Fuerte - Cabo Pantoja; a construção do novo aeroporto de Tena; a implementção do novo aeroporto de Coca; o Porto das Esmeraldas; e o Porto de Manta (IIRSA, 2008).

O projeto de melhoramento da navegabilidade do rio Napo apresenta resistência por parte de alguns grupos organizados como a Rede de Comunidades do rio Napo que são contra a construção da hidrovia, pois consideram prejudicial para as populações amazônicas (IIRSA, 2008; GREGORASCHUK, 2003).

Além disso, a região da bacia do rio Napo tem sofrido ao longo dos anos com a contaminação por hidrocarbonetos advindos da exploração de petróleo na região. Estudos demonstram que este tipo de contaminação gerou diversas resistências, principalmente de organizações indígenas (FONTAINE, 2005; BUSTAMANTE e JARRÍN, 2005). De acordo com Portillo (2009) do total de povos indígenas do Equador:

Muchos de ellos están assentados em la Amazonia y, por tanto, propensos a la actividad petroleira. La Vicepresidencia Corporativa de Responsabilidad Ambiental, Social, Seguridad y Salud de Petroecuador informó que al 25 de noviembre de 2008 existia una sobreposición de bloques petroleros que impactaba el hábitad de los pueblos Kichwas, Manta-Huancavilo y MantaHuancavilca. Y que, además, había incidencia sobre los territorios de las nacionalidades Shuar, Huaorani, Shiwiar, Achuar, Zapara y Secoya, entre otras. En muchos casos, el impacto de la actividad petrolera no sólo se limita a la ocupación de un área para la explotación de un yacimiento, sino al tendido de un gaseoducto o un oleoducto, que implica la deforestación, o al derrame de petróleo en la zona, tal como ocurrió el 14 de febrero de este año en la localidad amazónica de Santa Rosa (p. 7-8).

Já Fontaine (2005), aponta que a contaminação pelas atividades petroleiras no norte da Região Amazônica Equatoriana “está particularmente concentrada en los campos más antiguos y más productivos de la Amazonia ecuatoriana: Sacha e Shushufindi" (p. 37).

De acordo com o pronunciamento da Organização Kichwaruna Wangurina do Alto Napo, localizada no Departamento de Loreto no Peru, as novas concessões realizadas pelo governo do ex-presidente Alan Garcia Pérez à 
Tensão e conflitos na governança dos recursos hídricos amazônicos transfronteiriços. SANT'ANNA.

empresas petroleiras em territórios indígenas, sem a consulta das populações, é um desrespeito aos direitos destes povos. Assim, defendem:

Reconocemos los esfuerzos que como Pueblo hemos desarrollados, pero somos conscientes y vemos el abandono que sufren nuestro pueblos en las fronteras. Si queremos hacer un poco de historia, no queremos volver a vivir las consecuencias de lo que sucedió en la época del caucho. No queremos sufrir las consecuencias que hoy viven nuestros hermanos del río Corrientes y Pastaza. Queremos evitar que nuestro Napo, centro de nuestro vida, se vea una vez más afectado por el derrame petrolero, como así lo sufrieron los hermanos Kichwas del Ecuador, y como así lo vivieron hace poco nuestros hermanos del río Marañon (PRONUNCIAMIENTO, 2010).

Portanto, conclui-se que as dificuldades para a governança e gestão da bacia do rio Napo são muitos, principalmente devido às obras de infraestrutura previstas e a contaminação e o desmatamento ocasionados pela atividade petroleira. As diversas organizações existentes no Equador e no Peru não parecem agir em rede para a gestão transfronteiriça. No entanto, ainda é preciso aprofundar os estudos sobre esta região para uma análise comparada com a região da bacia do rio Acre.

\section{Considerações Finais}

Este trabalho busca contribuir para os estudos sobre o gerenciamento de bacias transfronteiriças numa perspectiva da geografia política admitindo-se que o acesso, a posse e o controle da água são questões de natureza política, pois interessam ao conjunto de uma coletividade e constitui elemento estruturante do território.
O compartilhamento de bacias pode levar a conflitos entre países ou pode agir como indutor da cooperação (RIBEIRO, 2008). Este é o caso da bacia Amazônica que é transfronteiriça e alvo de um projeto de gerenciamento conjunto dos recursos hídricos. A gestão compartilhada é uma forma de cooperação entre os países de bacias transfronteiriças por meio de ações coordenadas que visem garantir a quantidade, qualidade e acesso aos recursos hídricos. No entanto, o processo de governança parece apresentar dificuldades, já que as interações entre os países amazônicos oscilam entre cooperação e períodos de inatividade.

Além disso, as bacias do rio Acre e do rio Napo apresentam projetos de infraestrutura que têm gerado tensões e conflitos e também impactos sobre os recursos hídricos. A sociedade civil tem realizado iniciativas de governança que visam a gestão destas bacias transfronteiriças. $\mathrm{O}$ processo de governança que ocorre entre as instituições governamentais nacionais dos países amazônicos e a OTCA, em geral, se mostra mais lento do que a mobilização da sociedade civil, que em contato diário com a realidade destas bacias transfronteiriças precisam buscar soluções para os problemas emergentes. A governança destas bacias depende, então, da interação e ação em conjunto da sociedade civil, das instituições nacionais e da OTCA, como instituição que abarca a bacia como um todo. 


\section{Referencias Bibliográficas}

ALMEIDA, J. S.; REIS, V. L. e SILVA, M. M. F. Estado do Acre. In: INSTITUTO DE GESTÃO DAS ÁGUAS E CLIMA (INGÁ). Governança pública das águas: experiência dos estados brasileiros na gestão das águas. Salvador: INGÁ, 2009.

ALVAREZ W. e FADIGAS, E. A. F. A. Análisis del processo de integración elétrica PerúBrasil. 2010.

AMAYO Z., E. O impacto da Globalização na Amazônia e no Pacífico Sul-americano. In: AYERBE, L. F. (coord.). I ntegração latino americana e caribenha. São Paulo: Imprensa Oficial / Fundação Memorial da América Latina, 2007, p. 81-114.

ARAGÓN, L. E.; CLÜSENER-GODT, M. (org.). Problemática do uso local e global da água da Amazônia. Belém: NAEA, 2003.

BECKER, B. Amazônia: geopolítica na virada do III milênio. Rio de Janeiro: Garamond, 2006.

Inserção da Amazônia na geopolítica da água. In: ARAGÓN, L. E.; CLÜSENER-GODT, M. (org.). Problemática do uso local e global da água da Amazônia. Belém: NAEA, 2003, p. 273-298.

BOLíVIA. Visión Boliviana de la Cuenca Amazónica. Informe Final. Disponível em: <http://www.otca.info/gefam/index.php?pag $\mathrm{e}=$ HomePage $\&$ cat $=39>$. Acesso em: abril 2007.

BRASIL. Relatório Final do governo do Brasil. Visão da Bacia Amazônica. Disponível em: Disponível em: <http://www.otca.info/gefam/index.php?pag $\mathrm{e}=$ HomePage\&cat=39>. Acesso em: abril 2007.

BRASIL, Ivo. Gestão dos recursos hídricos como elemento de transformação da sociedade amazônica. In: ARAGÓN, L. E.; CLÜSENER-GODT, M. (org.). Problemática do uso local e global da água da Amazônia. Belém: NAEA, 2003.

BRITO, L. C. O Tratado de Cooperação Amazônica (TCA) e a sustentabilidade da região MAP (1992-2002). Dissertação (Mestrado em Direito). Programa
Interinstitucional UFSC/UFAC. Universidade Federal de Santa Catarina. Florianópolis, 2007.

BROWN, I. F. et al. Estrada de Rio Branco, Acre, Brasil aos Portos do Pacífico: como maximizar os benefícios e minimizar os prejuízos para o desenvolvimento sustentável da Amazônia Sul-Ocidental. Encuentro Internacional de Integración Regional. Lima, 2002.

et al. O MAP uma sigla de esforço e colaboração na região da amazônia sul-ocidental. In: COY, M e KOHLHEPP, G. (coord.). Amazônia Sustentável: desenvolvimento sustentável entre políticas públicas, estratégias inovadoras e experiências locais. Rio de Janeiro: Garamond, 2005.

BUSTAMANTE, T. e JARRIN, M. C. Impactos sociales de la actividad petroleira em Ecuador: um análisis de los indicadores. I conos. Revista de Ciencias Sociales. Quito: FLACSO, n. 21, jan. 2005, p. 19-34.

CAMARGO, E.; PEREIRA, M. R. S. e SANT'ANA, D. Q. Marco institucional e legal para a gestão de recursos hídricos na região MAP. In: REIS, V. (org.). Rumo à gestão participativa da Bacia do Alto Rio Acre: diagnóstico e avanços. Rio Branco: WWF / UFAC, 2007, p. 43-57.

CASTRO, J. E. Water Governance in the twentieth-first century. Ambiente e Sociedade. Campinas: v. 10, n. 2, 2007, p. 97-118.

CASTRO, E. Geopolítica da água e novos dilemas a propósito da Amazônia e seus recursos naturais. In: ARAGÓN, L. E.; CLÜSENER-GODT, M. (org.). Problemática do uso local e global da água da Amazônia. Belém: NAEA, 2003, p. 321-339.

CAUBET, Christian G. A água doce nas relações internacionais internacionais. Barueri: Manole, 2006.

COSTA-FILHO, A. Uma nova "OTCA" sob a velha ótica. In: ARAGÓN, L. E. e CLÜSENERGODT, M. (org.). Problemática do uso local e 
Tensão e conflitos na governança dos recursos hídricos amazônicos transfronteiriços. SANT'ANNA.

global da água na Amazônia. Belém: NAEA, 2003, p. 383-394.

DOUROJEANNI, M. J. Impactos socioambientales probables de la carretera transoceánica (Rio Branco - Puerto Maldonado - Ilo) y la capacidad de respuesta del Perú. Arequipa (Peru): Set 2001.

DOUROJEANNI, A. e J OURALEV, A. Evolución de políticas hídricas en América Latina y el Caribe. Bahia Análise e Dados. Salvador, V. 13, n. Especial, 2003, p. 347-355.

DUARTE, A. F. Medições de vazão e pluviometria na bacia do rio Acre, amostragem e análise físico-química da água. Relatório 1. Rio Branco: Universidade Federal do Acre, 2007.

DUDA, A. M.; UITTO, J. I. Management of transboundary water resources: lessos from internacional cooperation for conflict prevention. The Geographical Journal, v. 168, n. 4, dez, 2002, p. 365-378.

EQUADOR. Visión nacional para la gestión integrada de los Recursos hídricos en la cuenca del río amazonas. Informe Final. Disponível em: <http://www.otca.info/gefam/index.php?pag $\mathrm{e}=$ HomePage $\&$ cat $=39>$. Acesso em: abril 2009.

EQUADOR e PERU. Plan Binacional de Desarrollo de la región fronteiriza. Disponível em:

<http://www.planbinacional.gov.ec/index.ph p>. Acesso em: julho 2010.

FERRO, G. Three sides, three stories: the efforts to manage the tri-national basin of the Acre river. Dissertação de Mestrado. International Development Studies. Utrecht University, 2007.

FONTAINE, G. Microconflitos ambientales y crisis de gobernabilidad en la Amazonia ecuatoriana. Iconos. Revista de Ciencias Sociales. Quito: FLACSO, n. 21, jan. 2005, p. 35-46.

GERLAK, Andrea, K. Lesson learning and trans-boundary waters: a look at the Global Environment Facility's international waters program. Water Policy. V. 9, 2007, p. 55-72.

GIORDANO, Meredith A.; WOLF, Aaron. Sharing waters: Post-Rio internacional water management. Natural Resources Forum. Oxford, Malden: Blackwell Publihing, 2003, n. 27, p. 163-171.
. International River Basin

Management: Global Principles and Basin Practice. Dissertação de Ph.D em Geografia apresentada ao Departamento de Geociências da Universidade do Estado de Oregon (EUA). $2002 . \quad$ Disponível em <http:// www.transboundarywaters.orst.edu/ publications/Giordano-Meredith-2002.pdf>. Acesso em: dez. 2007.

international ${ }^{-1}$ freshwater agreements. Disponível em: <http:// www.transboundarywaters. orst. edu/ publications/atlas/atlas html/foreword/intern ationalAgreements.html>. Acesso em: $10 \mathrm{fev}$ 2008.

GREGORASCHUK, J. S. Desarrollo Sostenible del área fronteriza amazónica peruano ecuatoriano. FEMCIDI evaluación de Proyectos 2001. Montevideo (Uruguai), 2003.

IIRSA. Iniciativa para a Integração da Infraestrutura Regional Sul-Americana.. Disponível em: <http://www.iirsa.org>. Acesso em: jul 2008.

LAUTZE, J. et al. Putting the cart before the horse: water governance and IWRM. Natural Resources Forum. United Nations, v. 35, 2011, p. 1-8.

MACHADO, L. O. Interações na fronteira Brasiléia - Cobija, Brasil - Bolívia. Rio de J aneiro: UFRJ , 2001.

MANCHENO, D. e PIEDRA, A. La MantaManaos, estúdio económico regional: alcances, riesgos y potencialidades. Quito: Grupo Faro, 2008.

MAP. Inicitiva MAP. Disponível em: <http://www.map-amazonia.net>. Acesso em: jan 2007.

MIRUMACHI, Naho e ALLAN, J. A. Revisiting transboundary water governance: power, conflict, cooperation and political economy. Proceedings from CAIWA International Conference on Adaptative and Integrated Water Management: coping with scarcity, 1215 November, Basel, Switzerland, 2007.

MT Ministério dos Transportes. Informações detalhadas sobre o rio Acre. Disponível em: <http://www.transportes.gov. br/bit/hidro/det rioacre.htm>. Acesso em: dez 2008.

ORGANIZAÇÃO KICHWARUNA WANGURINA. Pronunciamiento de la Organización Kichwaruna Wangurina del Alto Napo. Monterrico de Angoteros (Peru), 2010. Disponível em: 
<http: //reduncayali. blogspot.com/2010/09/p ronunciamiento-de-la-organizacion. html>. Acesso em jan 2011.

OTCA. Projeto de Gerenciamento Integrado e Sustentável dos Recursos Hídricos Transfronteiriços na Bacia do Rio Amazonas Considerando a Variabilidade e as Mudanças Climáticas. Disponível em: <http://www.otca.org. br/gefam/index.php?p age $=$ HomePage $\&$ cat $=34>$. Acesso em: 23 jul. $2007 a$.

Integrando la Amazonía Continental: Informe de Gestión de mayo de 2004 a octubre de 2005. Dispinível em: <http://www. otca.org. br/br/integrando.php> . Acesso em: ago 2006.

Co-ntine--ital: $\begin{gathered}\text { Integrando a Amazônia } \\ \text { Relatório de }\end{gathered}$ novembro de 2005 a outubro de 2006 . Disponível em: <http://www.otca.org.br/br/integrando.php> . Acesso em: jun 2007b.

Relatório de Gestão: julho de 2007 a julho de 2008. Disponível em: <http://www. otca.org.br/br/>. Acesso em: jan 2009b.

OTCA, PNUMA e GEF. Integrated and Sustainable Management of Transboundary Water Resources in the Amazon River Basin Considering Climate Variability and Climate Change - Request for CEO endorsement. 2009.

PAULA, E. A. e SOUZA, I. P. D. Ambientalização, territorialização/desterritorialização, na fonteira trinacional amazônica (Peru, Brasil e Bolívia). Trabalho apresentado no IV Encontro Nacional da ANPPAS. Brasília: 2008.

PEREIRA, M. R. S. Iniciativa MAP: um emergente movimento social transfronteiriço e sua gestão no desenvolvimento sustentável na região da Amazônia Sul Ocidental. Dissertação (Mestrado em Direito). Programa Interinstitucional UFSC/UFAC. Universidade Federal de Santa Catarina. Florianópolis, 2007.

PERU. Bases para una visión nacional común de Desarrollo de la Amazonia Peruana. Informe Final. Disponível em: Disponível em: <http://www.otca.info/gefam/index.php?pag $\mathrm{e}=$ HomePage\&cat $=39>$. Acesso em: abril 2007.

PLANO Estratégico 2004/12. Disponível em: <http://www.otca.org.br/br/plano.php>. Acesso em: 10 fev. 2004.
PNUMA; OTCA e CIUP. Geo Amazônia. Disponível em: <http://www.pnuma.org/deatl/geoamazonia />. Acesso em: fev 2009.

PORTILLO, S. V. La integración de la Comunidad Andina en el debate de la explotación petrolera en territorios indígenas. Maestria Gobernanza energética, Programa Estudios Socioambientales FLACSO Ecuador. Quito: FLACSO, 2009.

PRISCOLI, Jerome Delli e WOLF, Aaron T. Managing and Transforming Water Conflicts. Cambridge: Cambridge University Press, 2009.

QUEROL, Maria. Estudio sobre los convenios e acuerdos de cooperación entre los países de América Latina y el Caribe, en relación con sistemas hídricos y cuerpos de agua transfronteirizos. Serie Recursos Naturales e Infraestructura. Santiago de Chile: CEPAL, 2003.

RAFFESTIN, C. Por uma geografia do poder. São Paulo: Ática, 1993.

RAVENA, N. et al.. Gestão das Águas na Amazônia: atores sociais, marcos regulatórios e escalas. Trabalho apresentado no IV Encontro Nacional da ANPPAS. Brasília: 2008.

REIS, V. (org.). Rumo à gestão participativa da Bacia do Alto Rio Acre: diagnóstico e avanços. Rio Branco: WWF / UFAC, 2007.

REIS, V. et al. Aspectos Biogeofísicos da Bacia do Alto Rio Acre. In: REIS, V. (org.). Rumo à gestão participativa da Bacia do Alto Rio Acre: diagnóstico e avanços. Rio Branco: WWF / UFAC, 2007, p. 7-24.

RIBEIRO, Wagner C. A ordem ambiental internacional. São Paulo: Contexto, 2001.

Geografia Política da Água. São Paulo: Annablume, 2008.

Impasses da governança da água no Brasil. In: RIBEIRO, W. C. (org.). Governança da água no Brasil: uma visão interdisciplinar. São Paulo: Annablume, 2009.

SAMPAIO, C. H. S. Relatório do Grupo de Trabalho do Rio Acre. Rio Branco: Conselho Nacional de Recursos Hídricos, 2010.

SNEDDON, C e FOX, C. Rethinking transboundary waters: a critical hydropolitics of the Mekong basin. Political Geography. V. 25, 2006, p. 181-202. 
Tensão e conflitos na governança dos recursos hídricos amazônicos transfronteiriços. SANT'ANNA.

TCA. Tratado de Cooperação Amazônica. Disponível em:

<http://www.otca.org.br/br/institucional/inde x.php?id=10> . Acesso em: 10 fev. 2004.

WARNER, J eroen e WEGERICH, Kai. Is water politics? Towards international water relations. In: WARNER, Jeroen e WEGERICH, Kai (eds.). The politics of water: a survey. London/New York: Routledge, 2010, p. 3-17.

WOLF, Aaron; STAHL, Kerstin.; MACOMBER, F. Macomber. Conflict and cooperation within international river basins: the importance of institutional capacity. Annual meeting of the International Studies Association. Portland, 2003. Disponível em: <http://www.transboundarywaters.orst.edu/ publications/conflict_coop/>. Acesso em: dez. 2007.

ZEITOUN e MIRUMACHI. Transboundary water interaction: reconsidering conflict and co-operation. In: WARNER, Jeroen e WEGERICH, Kai (eds.). The politics of water: a survey. London/New York: Routledge, 2010, p. 96-118. 